\title{
HARDENING-RELATED DEFORMATIONS OF GEAR WHEELS AFTER VACUUM CARBURISING AND QUENCHING IN GAS
}

\author{
Wojciech Stachurski ${ }^{1}$, Piotr Zgórniak' ${ }^{1}$, Jacek Sawicki ${ }^{1}$, Mateusz Przybysz $^{1}$ \\ 1 Institute of Machine Tools and Production Engineering, Faculty of Mechanical Engineering, Lodz University \\ of Technology, 1/15 Stefanowskiego Street, 90-924 Łódź, Poland, e-mail: wojciech.stachurski@p.lodz.pl, piotr. \\ zgorniak@p.lodz.pl, jacek.sawicki@p.lodz.pl, 174490@edu.p.lodz.pl
}

Received: 2016.12.15

Accepted: 2017.02.01

Published: 2017.03.01

\begin{abstract}
The purpose of modern surface hardening technology is obtaining reproducible, precisely planned parameters of the carburized layer, minimizing the negative phenomena that result in dimensional changes after hardening and making it possible to determine the nature and magnitude of these changes. This concerns mainly the concept of singlepiece flow in heat treatment applied for the purposes of mass production, employing a special autonomous 4D Quenching chamber for high pressure gas quenching (HPGQ). The main components of the 4D Quenching chamber include a system of cooling nozzles surrounding the processed item and providing a uniform inflow of cooling gas from all directions (3D) and a table rotating together with the item processed, contributing to uniform cooling (4D). Within the framework of this paper there was studied the impact of gear wheel quenching in a 4D Quenching chamber using nitrogen at pressure of 6 and 10 bar on changes in geometry. Geometric measurements of facewidth of gear, hole diameter and outside diameter were performed before and after carburization and quenching. The results obtained allowed us to determine the impact of quenching pressure inside a 4D Quenching chamber on dimensional changes in gear wheels analyzed. The thermo-chemical treatment resulted in a decrease in outside diameters and hole diameters measured and an increase in facewidth of gears.
\end{abstract}

Keywords: gas quenching, geometric measurement, hardening-related deformations, gear wheels.

\section{INTRODUCTION}

Carburizing followed by quenching is the most popular surface treatment method in the automotive industry. Low-pressure carburizing $[6,7$, $16]$ is better than conventional carburizing $[4,5]$ in terms of efficiency and it is characterized by a number of advantages, such as lack of internal oxidation, higher uniformity of resulting layers, good energy efficiency and environmental friendliness. At the same time there is a constant increase in requirements regarding, among others, minimizing the negative phenomena resulting in dimensional changes after hardening and enabling the determination of nature and magnitude of these changes $[1,3]$. The answer to these requirements is the concept of single-piece flow treatment, in which every single item passes through the same process stages and conditions $[10 \div 15]$. While passing through the process chambers with stabilized parameters, the item is subjected to identical process conditions, which ensures very high precision and reproducible results of carburizing. In addition, the HPGQ (high pressure gas quenching) 4D Quenching chamber (Fig. 1) intended for individual gas cooling enables unrestricted adjustment of the cooling curve and obtaining the optimal microstructure and properties of steel. An important feature of this solution is the application of a system of cooling nozzles surrounding the gear wheel 


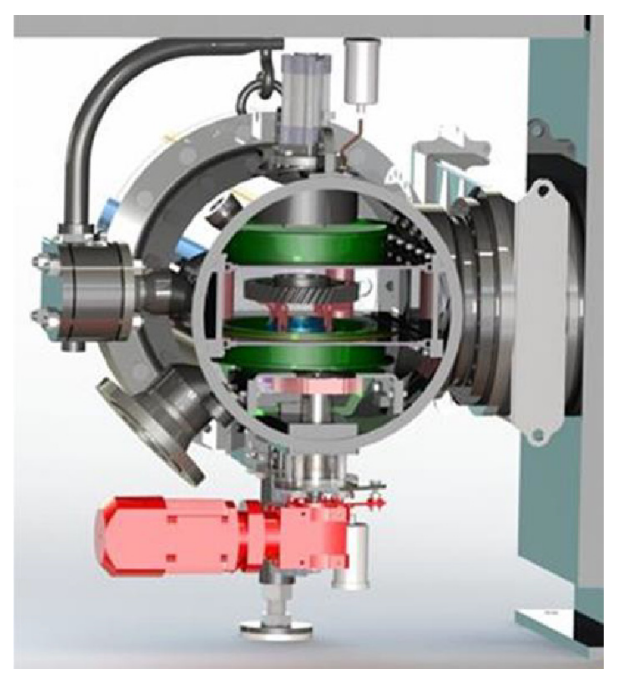

Fig. 1. 4D Quenching chamber for HPGQ [14]

and ensuring uniform inflow of cooling gas from all directions (3D). At the same time, uniform distribution of cooling is supported by the table rotating together with the gear wheel (4D). This type of cooling system, using nitrogen at pressure of up to 15 bar, enables obtaining the cooling intensity comparable to oil-based systems, without the necessity of using Helium (He). The application of a method consisting in controlled hardening of individual parts reduces to minimum the deformations of every such part and provides complete reproducibility of deformations on identical parts. At the same time, it allows obtaining above-average mechanical properties.

Within the framework of this paper there were compared deformation measurement results for selected parameters of gear wheels that underwent carburization in a vacuum furnace employing the single-piece flow method and quenching with nitrogen at pressure of 6 and 10 bar in a 4D Quenching chamber.

\section{METHODOLOGY}

The experimental research involved a series of 10 external spur gears and an involute profile made of EN $20 \mathrm{MnCr} 5$ steel. The nominal geometric parameters of the gear wheels tested are summarized in Table 1.

Hobbed gear wheels were subjected to vacuum carburizing in a single-piece flow furnace at $950^{\circ} \mathrm{C}$, achieving the effective case depth of ECD $=0.55 \mathrm{~mm}$. Subsequently, 5 gear wheels were quenched in a 4D Quenching chamber at 10 bar
Table 1. The nominal geometric parameters of gear wheels tested

\begin{tabular}{|l|c|}
\hline \multicolumn{1}{|c|}{ Parameter } & Value \\
\hline Normal module $\mathrm{m}_{\mathrm{n}}, \mathrm{mm}$ & 1.75 \\
\hline Number of teeth $\mathrm{z}$ & 58 \\
\hline Outside diameter $\mathrm{d}_{\mathrm{a}}, \mathrm{mm}$ & 105 \\
\hline Root diameter $\mathrm{d}_{\mathrm{f}}, \mathrm{mm}$ & 97.125 \\
\hline Pitch diameter $\mathrm{d}, \mathrm{mm}$ & 101.5 \\
\hline Hole diameter $\mathrm{d}_{\mathrm{o}}, \mathrm{mm}$ & $30 \mathrm{H} 7$ \\
\hline Facewidth of gear $\mathrm{b}, \mathrm{mm}$ & 14.5 \\
\hline Pressure angle $\alpha,{ }^{\circ}$ & 20 \\
\hline Helix angle $\beta,{ }^{\circ}$ & 0 \\
\hline Coefficient of shift profile $\mathrm{x}, \mathrm{mm}$ & 0 \\
\hline
\end{tabular}

Table 2. Thermo-chemical treatment (TCT) parameters

\begin{tabular}{|c|c|c|}
\hline $\begin{array}{c}\text { Gear wheel } \\
\text { designation }\end{array}$ & \multicolumn{2}{|c|}{ Parameters of treatment } \\
\hline $\mathrm{K} 10$ & $\begin{array}{c}\text { Quenching in nitro- } \\
\text { gen at } 10 \text { bar and } \\
\text { at a temperature of } \\
850^{\circ} \mathrm{C}\end{array}$ & $\begin{array}{c}\text { Tempering at } \\
190^{\circ} \mathrm{C} \text { for } 180 \text { min }\end{array}$ \\
\hline $\mathrm{K} 06$ & $\begin{array}{c}\text { Quenching in nitro- } \\
\text { gen at } 6 \text { bar and at a } \\
\text { temperature of } 850^{\circ} \mathrm{C}\end{array}$ & $\begin{array}{c}\text { Tempering at } \\
190^{\circ} \mathrm{C} \text { for } 180 \text { min }\end{array}$ \\
\hline
\end{tabular}

and the remaining 5 at 6 bar. In the quenching chamber, the orientation of tooth designated as no. 1 was identical for the entire gear wheel series. After quenching, the gear wheels were tempered at $190^{\circ} \mathrm{C}$ for 3 hours. The thermo-chemical treatment (TCT) parameters are given in Table 2.

In order to determine the hardening-related deformations in gear wheels after vacuum carburization, gas quenching and tempering, the geometric measurements were conducted both before and after thermo-chemical treatment. In order to perform measurements there was used a DEA Global Performance 5.7.5 coordinate measuring machine featuring temperature compensation. The PC-DMIS CAD++ software was used to control the machine's working motion and create its measurement programs.

An original program for measuring gear wheels was created using an algorithm based on recommendations available in the literature $[2,8$, 9]. The coordinate system of a gear wheel measured was defined in the machine's working space on the hole diameter, top face of toothed-wheel rim and tooth designated as no.1. [9, 17].

Three geometric parameters of the gear wheels were selected for the purposes of comparative analysis: 

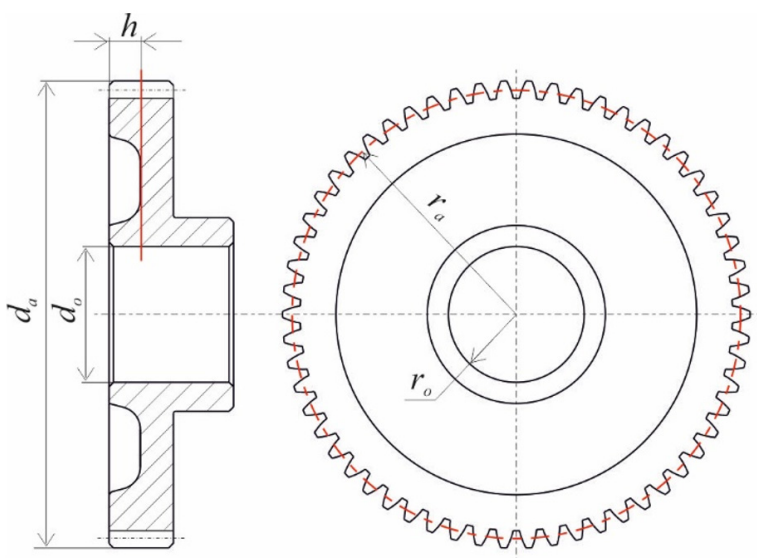

Fig. 2. Diameters, radii and measurement height for the $\mathrm{K} 10$ and K06 wheels

- Chordal tooth thickness $s$ - the thickness was measured for 58 teeth. The shortest distance between two measurement points located on two flanks of measured tooth on the pitch diameter $d$ (chord measurement), at the height $h$ equal to half of the facewidth of gear was adopted as the thickness of a single tooth (Fig. 2).

- Hole diameter $d_{o}$ - after designating the coordinate system origin, 58 measurement points located in the gear wheel mounting hole (hole diameter) at the height $h$ (Fig. 2) were measured. Then the values of 58 radii $r_{o}$ were calculated. To determine the hole diameter $d_{o}$ for each gear wheel the least squares method was used.

- Outside diameter $d_{a}$ - after designating the coordinate system origin, 58 measurement points on the outside diameter at the height $h$ were measured (Fig. 2). Then there were calculated the values of 58 radii $r_{a}$, which were subsequently used to determine the outside diameter $d_{a}$ using the least squares method.

Measurement uncertainty of the coordinate measuring machine is determined according to ISO 10360 standard. The maximum permissible measurement error when measuring length (distance, diameter, position) $\mathrm{MPE}_{\mathrm{E}}$ is:

$$
M P E_{E}=1,5+\frac{L}{333}[\mu m]
$$

where: $\mathrm{L}$ - measurement length [mm].

The MATLAB software was used for elaborating statistics on the basis of results obtained. Due to the possibility of outliers, a median was used to determine the average values. The whole elaboration was illustrated using box plots.

\section{RESULTS AND DISCUSSION}

\section{Chordal Tooth Thickness (s)}

Figure 3 shows the graph presenting the thickness of the individual teeth of the K10 and K06 gear wheels, measured before and after thermochemical treatment.

It is worth to notice that the bars representing the thickness of individual teeth create waves of a certain amplitude, whereas for the values measured before and after the TCT, their courses overlap. Such form of the thickness variation course for individual teeth in a gear wheel results from radial runout of a gear blank during mechanical processing that are impossible to eliminate and is not related to the subsequent thermo-chemical treatment. At the same time, it can be observed that the thickness of individual teeth after TCT behaves in a non-uniform manner - in some cases it increases, in other - decreases. Figure 4 shows the differences in thickness between individual teeth resulting from TCT (thermo-chemical treatment).

When analyzing the graphs shown in Figure 4 it has to be noted that the aforementioned nature of changes in thickness of individual teeth means that on the toothed-wheel rim circumference there are present, in alternating manner, the areas where chordal tooth thickness values increase as a result of TCT and the areas where these values decrease after TCT. This is caused by the arrangement of cooling nozzles, particularly during the first stage of the cooling agent feeding.

Table 3 shows the outcome of statistical elaboration of the differences between thickness of individual teeth of both gear wheels that were observed.

Figure 5 shows a graphical elaboration of results in the form of a box plot.

Table 3. Values of chordal tooth thickness difference parameters

\begin{tabular}{|l|c|c|}
\hline \multirow{2}{*}{\multicolumn{1}{|c|}{ Parameters }} & \multicolumn{2}{c|}{ Values } \\
\cline { 2 - 3 } & K10 & K06 \\
\hline Max. & 0.032 & 0.032 \\
\hline Upper Whisker & 0.032 & 0.032 \\
\hline Q3 (75\%) & 0.011 & 0.016 \\
\hline Q2 (50\%) - median & 0.004 & 0.008 \\
\hline Q1 $(25 \%)$ & -0.025 & -0.020 \\
\hline Lower Whisker & -0.058 & -0.058 \\
\hline Min. & -0.058 & -0.058 \\
\hline Number of points $\mathrm{n}$ & 58 & 58 \\
\hline Number of outliers & 0 & 0 \\
\hline
\end{tabular}


a)

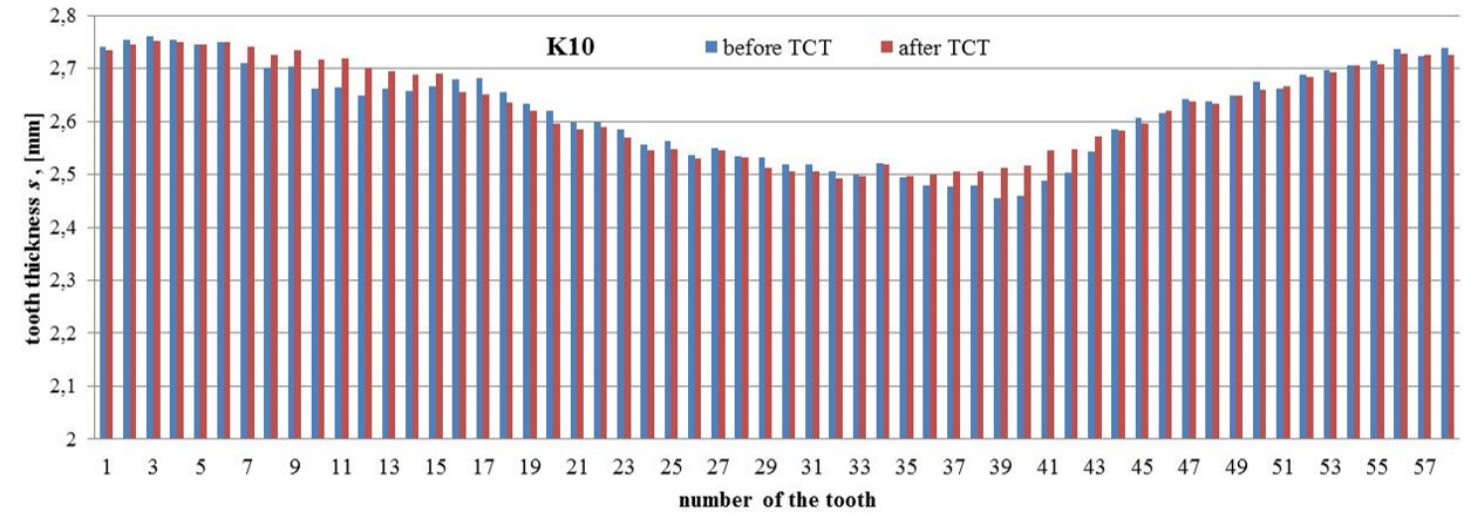

b)

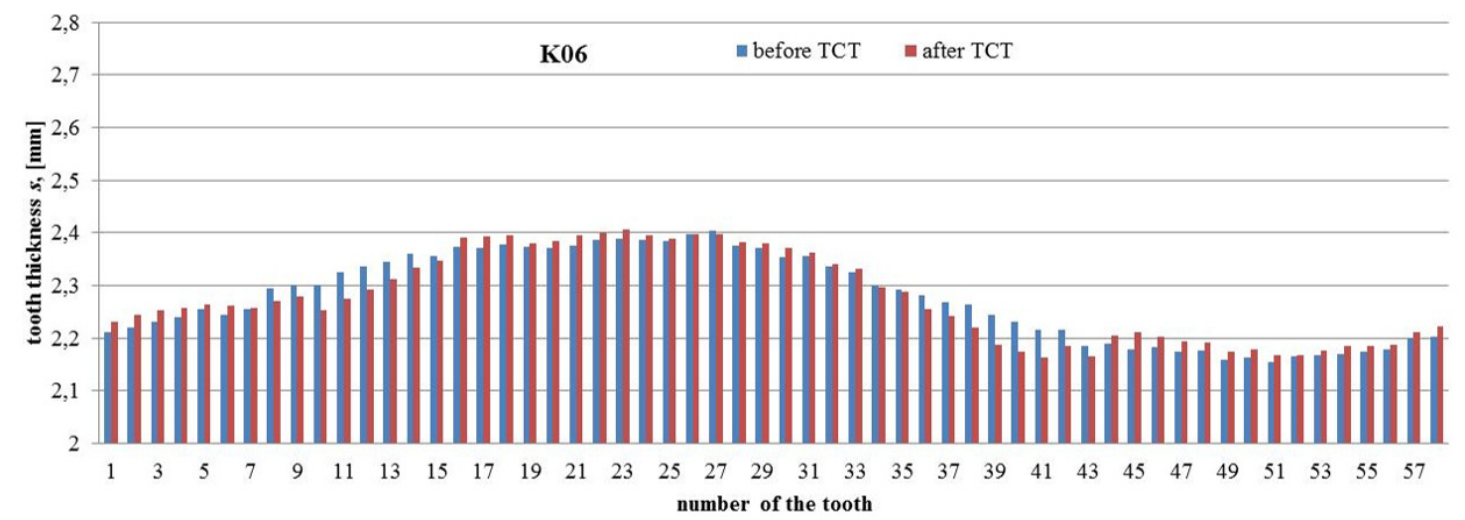

Fig. 3. Thickness of the individual teeth measured before and after the TCT: a) K10 gear wheel, b) K06 gear wheel

a)

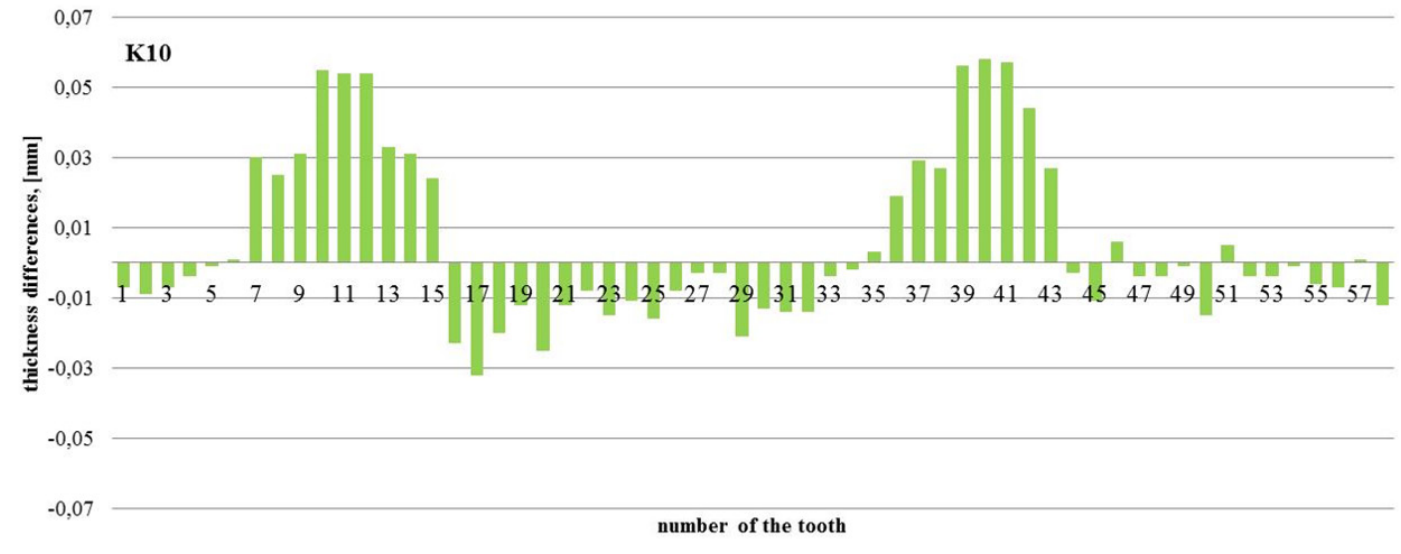

b)

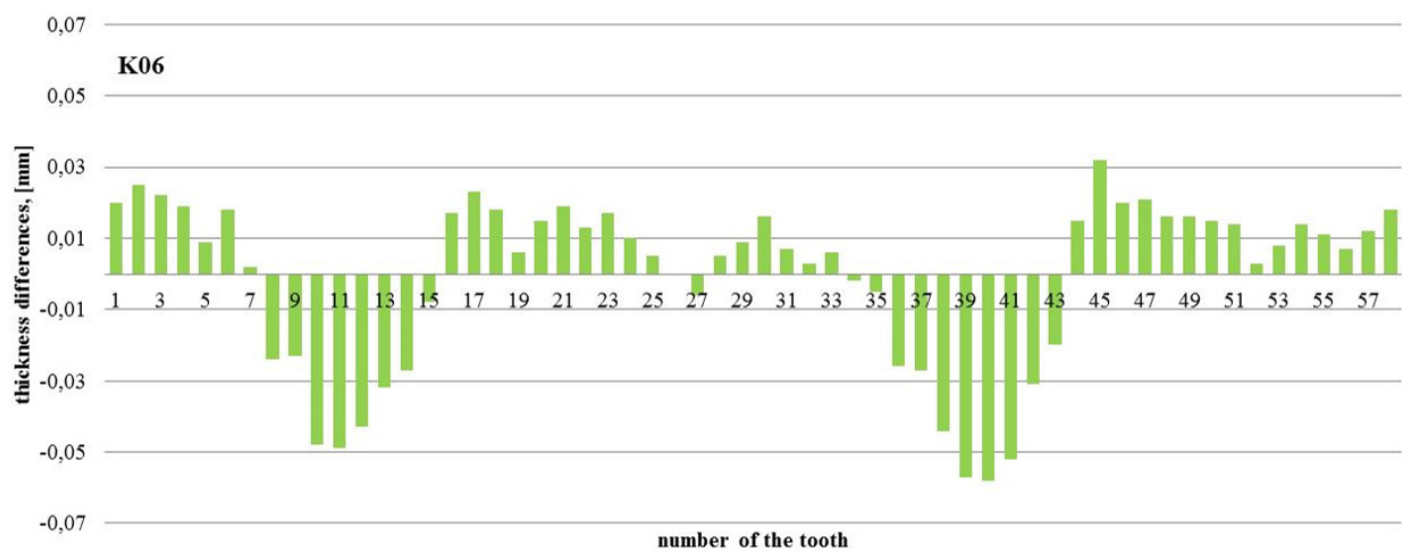

Fig. 4. Differences in thickness between individual teeth resulting from TCT: a) K10 gear wheel, b) K06 gear wheel 


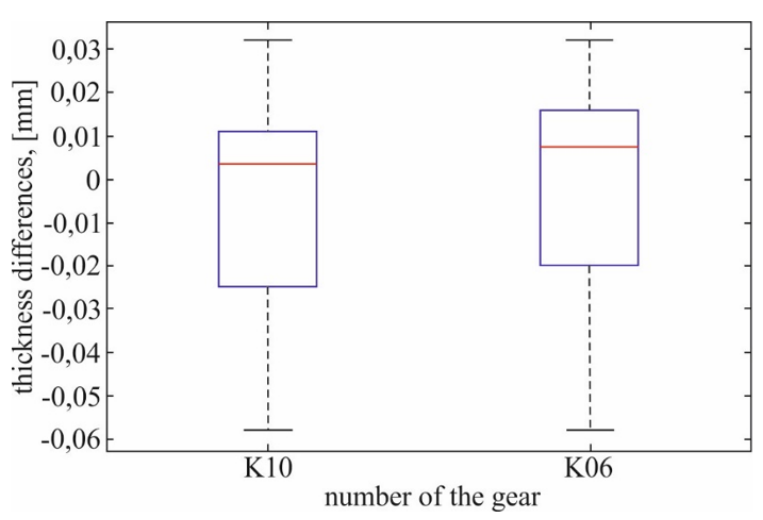

Fig. 5. Box plot for the tooth thickness difference values, K10 and K06 wheels

On the basis of median value given in Table 3 and illustrated on Figure 5, it must be stated that as a result of thermo-chemical treatment the chordal tooth thickness increased for both gear wheels. In case of the K06 gear wheel, for which a lower cooling gas pressure (6 bar) was applied, there was found a $0.008 \mathrm{~mm}$ increase in chordal tooth thickness. In case of the K10 gear wheel, for which a higher cooling gas pressure (10 bar) was applied, the increase in chordal tooth thickness is smaller and amounts to $0.004 \mathrm{~mm}$, that is, $50 \%$ of the thickness increase value for the K06 gear wheel.

\section{Hole Diameter $\left(D_{0}\right)$}

Figure 6 presents a graph showing the shape of the mounting hole measured, resulting from

a)

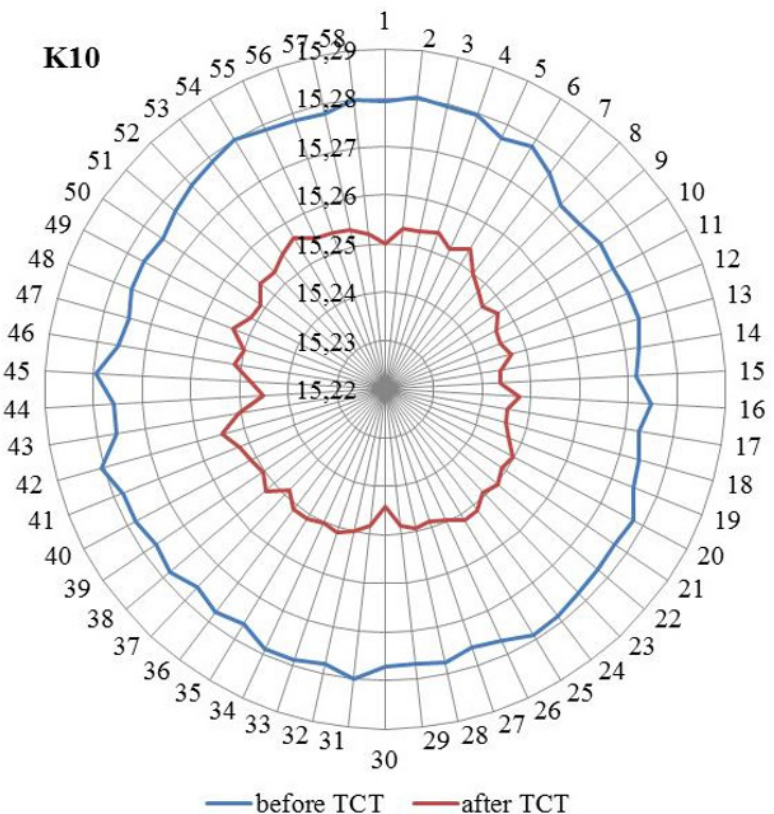

measurements of the radius $r_{o}$. The curves on the graph correspond to the values of radii measured before and after the thermo-chemical treatment.

On the basis of the above graphs it can be stated that as a result of the thermo-chemical treatment (TCT) the hole diameters of both gear wheels experienced a uniform change. This is evidenced by the graphs on Figure 7, which show the differences between values of the radii $r_{o}$ of the gear wheels measured that were caused by TCT.

Table 4 contains results of the statistical elaboration of the values of differences between radii $r_{o}$ of the hole diameters for both gear wheels.

Figure 8 shows the graphical elaboration of results in the form of a box plot.

Table 4. Values of difference parameters for radii $r_{o}$ of hole diameters

\begin{tabular}{|l|c|c|}
\hline \multirow{2}{*}{\multicolumn{1}{|c|}{ Parameters }} & \multicolumn{2}{c|}{ Values } \\
\cline { 2 - 3 } & K10 & K06 \\
\hline Max. & -0.022 & -0.020 \\
\hline Upper Whisker & -0.022 & -0.020 \\
\hline Q3 (75\%) & -0.025 & -0.023 \\
\hline Q2 (50\%) - median & -0.027 & -0.024 \\
\hline Q1 (25\%) & -0.028 & -0.025 \\
\hline Lower Whisker & -0.032 & -0.029 \\
\hline Min. & -0.033 & -0.032 \\
\hline Number of points $\mathrm{n}$ & 58 & 58 \\
\hline Number of outliers & 1 & 2 \\
\hline
\end{tabular}

b)

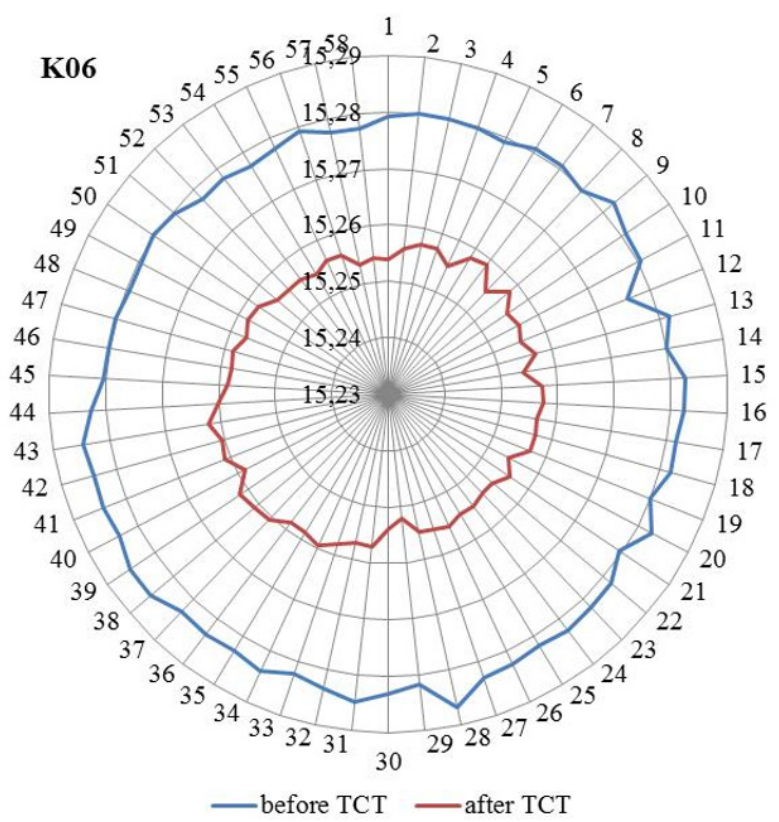

Fig. 6. Graph of changes in the radius $r_{o}$ before and after TCT: a) K10 gear wheel, b) K06 gear wheel 

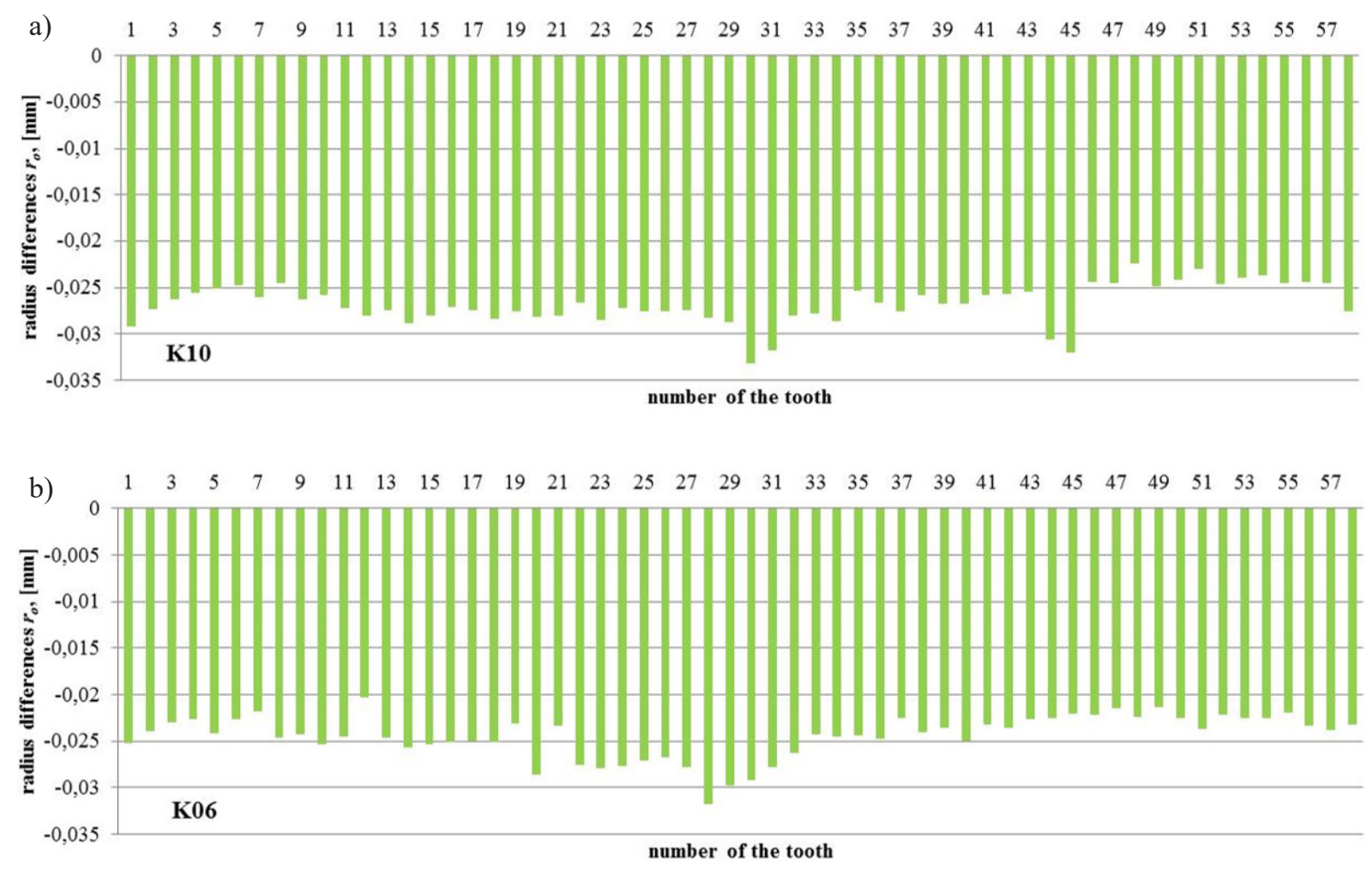

Fig. 7. Differences in the radius $r_{o}$ values resulting from TCT: a) K10 gear wheel, b) K06 gear wheel

On the basis of the median value provided in Table 4 and illustrated on Fig. 8 it must be stated that as a result of thermo-chemical treatment the value of radii $r_{o}$ of mounting hole decreased in both cases. It is obvious that the hole diameters $d_{o}$ changed as well in consequence. In case of the K06 gear wheel, for which a lower cooling gas pressure ( 6 bar) was applied, there was found a decrease in the retaining radius $r_{o}$ by $0.024 \mathrm{~mm}$. In case of the K10 gear wheel, for which a higher cooling gas pressure (10 bar) was applied, the radius decreased by $0.027 \mathrm{~mm}$.

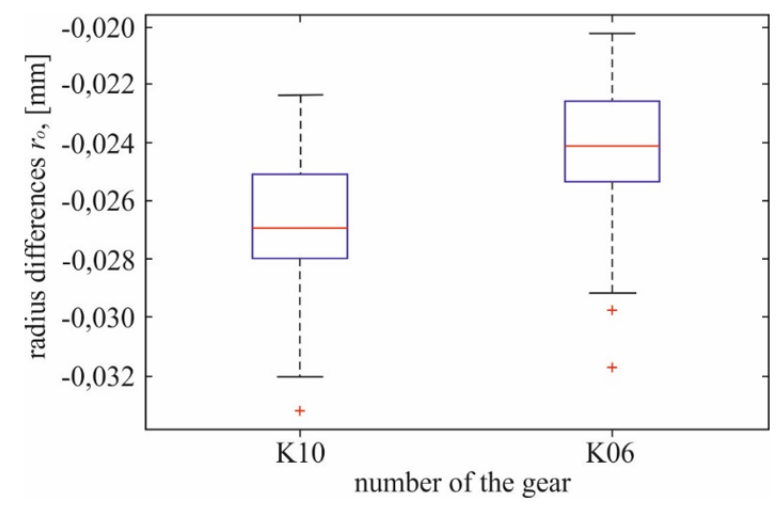

Fig. 8. Box plot for values of differences between the radii $r_{o}$ of mounting hole; K10 and K06 gear wheels

\section{OUTSIDE DIAMETER $\mathrm{D}_{\mathrm{A}}$}

Fig. 9 presents a graph showing the shape of circle measured on the outside surface, resulting from measurements of the radius $r_{a}$. The curves on the graph correspond to the values of radii measured before and after the thermo-chemical treatment.

On the basis of the above graphs it can be stated that as a result of the thermo-chemical treatment there occurred a decrease in diameters of circles measured on outside diameters of both gear wheels. It is easy to notice the asymmetry of the measured circles' location in relation to the determined origin of the coordinate system. This is caused by errors in generation of the cylindrical surface of gear blank that are impossible to eliminate entirely and is not related to the subsequent thermo-chemical treatment.

Graphs on Fig. 10 show the differences between the radii $r_{a}$ values resulting from TCT.

When analyzing the graphs shown on Fig. 10 it should be noted that on the toothed-wheel rim circumference there are present, in alternating manner, the areas where differences between the outside radii $r_{a}$ values either increase or decrease. According to the authors, this is caused by the arrangement of cooling nozzles, 
a)

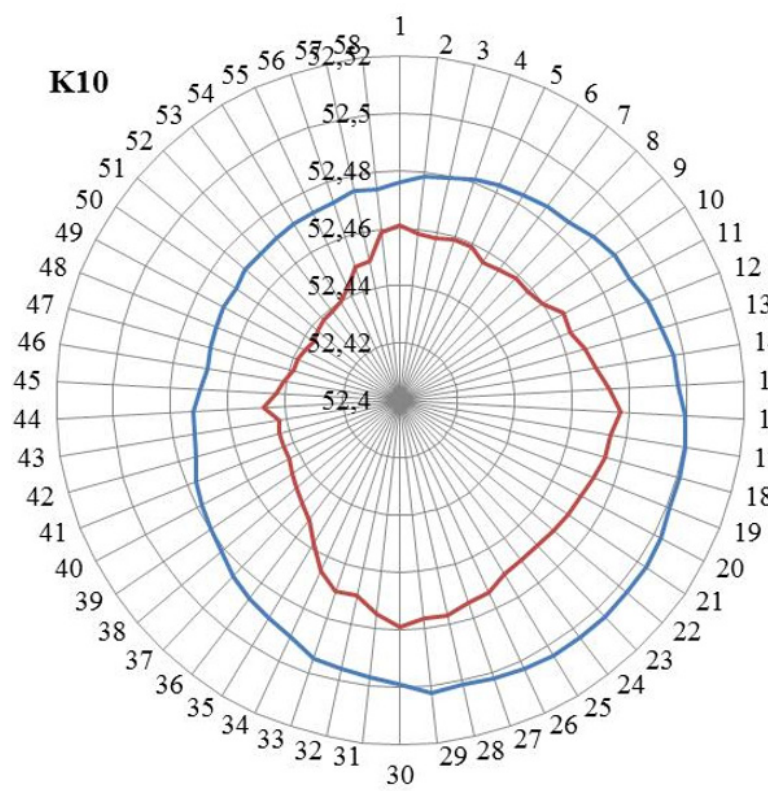

—before TCT —after TCT b)

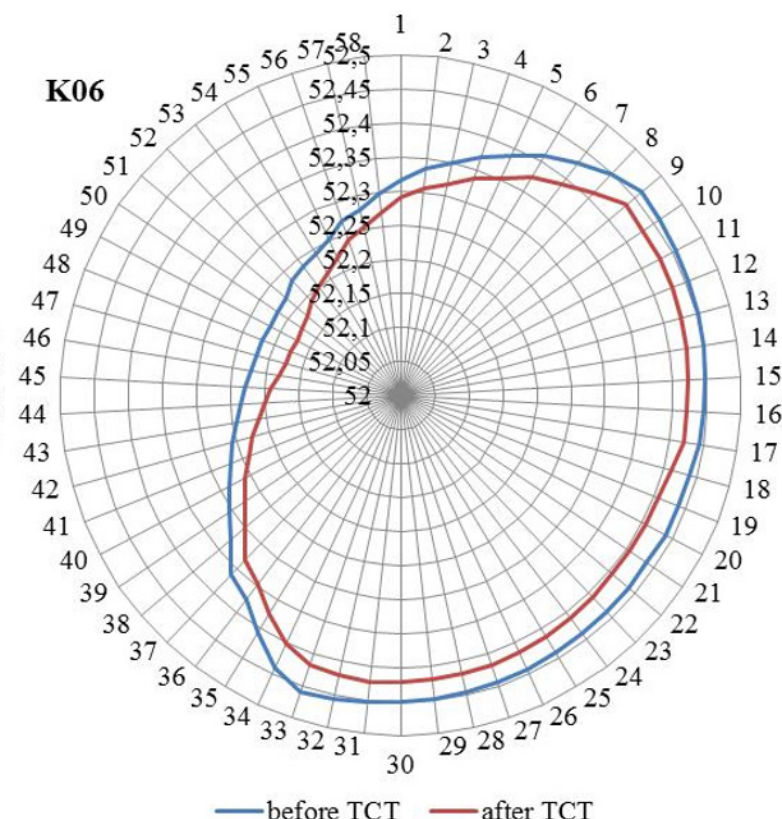

Fig. 9. Graph of changes in the radius $r_{a}$ before and after TCT: a) K10 gear wheel, b) K06 gear wheel
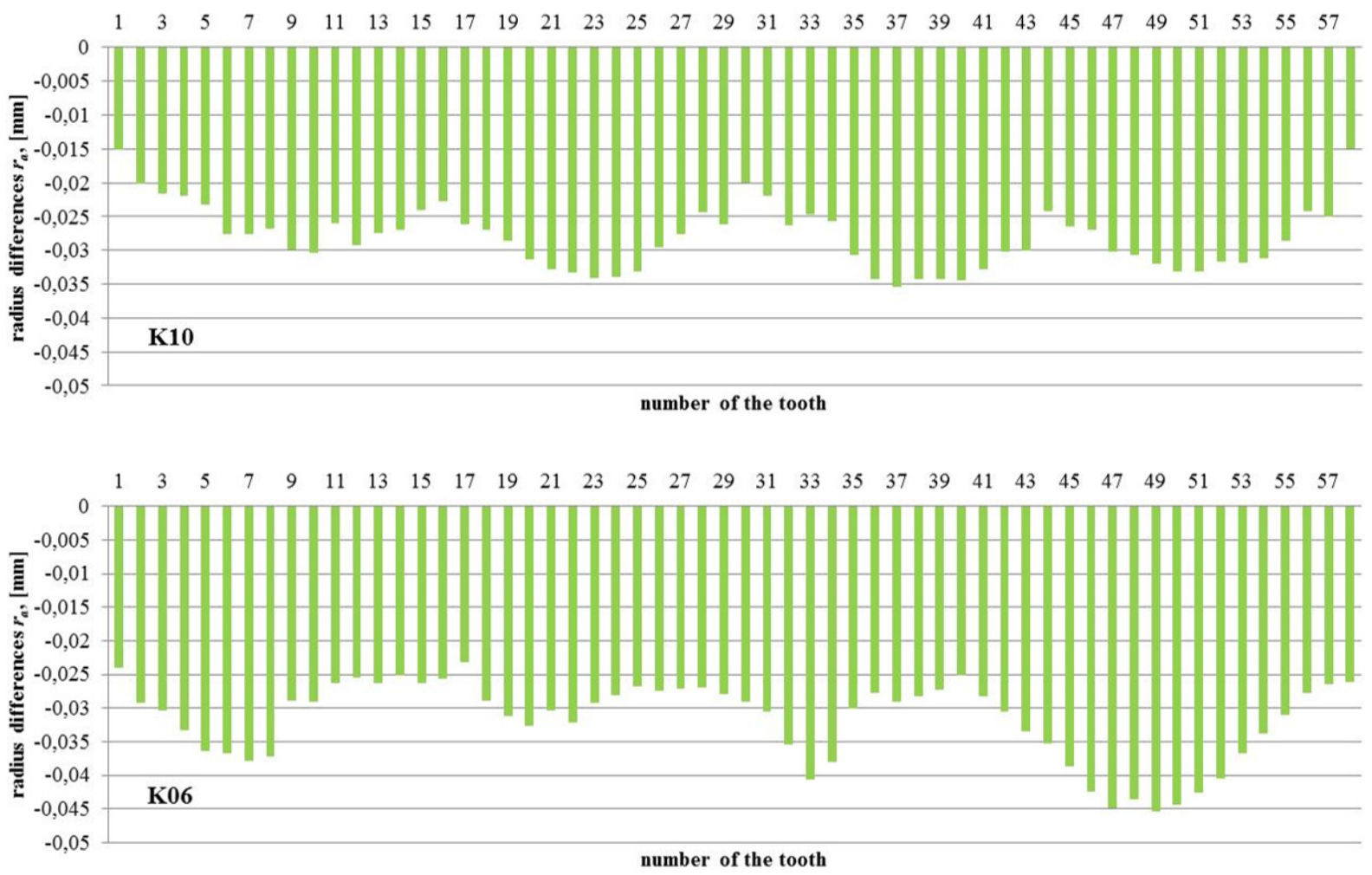

Fig. 10. Differences in radius $r_{a}$ values resulting from TCT: a) K10 wheel, b) K06 wheel

particularly during the first stage of cooling agent feeding, similarly to the case of chordal tooth thickness.

Table 5 contains the results of statistical elaboration of the differences between the outside radii $r_{a}$ for both gear wheels. Figure 11 shows a graphical elaboration of results in the form of a box plot.

On the basis of median value provided in Table 5 and illustrated on Figure 11 it must be 
Table 5. Values of difference parameters for outside radii $r_{a}$

\begin{tabular}{|l|c|c|}
\hline \multirow{2}{*}{ Parameters } & \multicolumn{2}{c|}{ Values } \\
\cline { 2 - 3 } & K10 & K06 \\
\hline Max. & -0.017 & -0.023 \\
\hline Upper Whisker & -0.017 & -0.023 \\
\hline Q3 (75\%) & -0.026 & -0.031 \\
\hline Q2 (50\%) - median & -0.028 & -0.035 \\
\hline Q1 (25\%) & -0.032 & -0.038 \\
\hline Lower Whisker & -0.038 & -0.042 \\
\hline Min. & -0.038 & -0.042 \\
\hline Number of points $\mathrm{n}$ & 58 & 58 \\
\hline Number of outliers & 1 & 0 \\
\hline
\end{tabular}

stated that as a result of thermo-chemical treatment the values of outside radii $r_{a}$ decreased in both cases. It is obvious that the $d_{a}$ outside diameters decreased as well in consequence. In case of the K06 gear wheel, for which a lower cooling gas pressure ( 6 bar) was applied, there was found a decrease in the mounting hole radius by 0.035 $\mathrm{mm}$. In case of the K10 gear wheel, for which a higher cooling gas pressure (10 bar) was applied, there radius decreased by $0.028 \mathrm{~mm}$.

\section{CONCLUSIONS}

On the basis of the results obtained it is possible to formulate the following conclusions:

1. The chordal tooth thickness value $s$ increases under the influence of thermo-chemical treatment, whereas the greater thickness values were obtained at the lower gas pressure.

2. As a result of thermo-chemical treatment there occurred a decrease in value of mount-

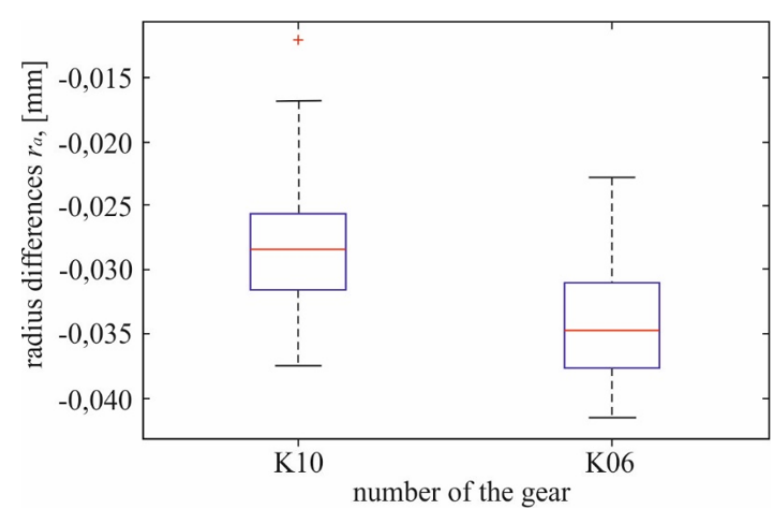

Fig. 11. Box plot for the values of differences between the outside radii $r_{a}$; K10 and K06 gear wheels ing hole radii $r_{o}$, whereas the greater values of radii were obtained at the lower gas pressure. Therefore, the application of higher cooling gas pressure results in smaller hole diameter $d_{o}$ than in case of application of lower cooling gas pressure.

3. As a result of the thermo-chemical treatment the outside radii $r_{a}$ decreased, whereas the greater values of radii were obtained for higher gas pressure. Therefore, the application of higher cooling gas pressure results in smaller diameter of the cylindrical outside surface than in the case of application of lower cooling gas pressure.

4. In order to minimize the amplitude of deformations after quenching, the operation of HPGQ 4D Quenching chamber has to be optimized with regard to the changes in shape of nozzle manifold and the operating parameters.

\section{Acknowledgments}

The research and publication were financed by the National Centre for Research and Development as part of project no. POIR.04.01.04-000087/15 entitled: "Equipment for high performance and precise heat treatment with a quenching deformation reduction system for direct application in downstream production chains of mechanical gearing and bearings".

\section{REFERENCES}

1. Atraszkiewicz R., Januszewicz B., Kaczmarek Ł., Stachurski W., Dybowski K. and Rzepkowski A. High pressure gas quenching: Distortion analysis in gears after heat treatment. Materials Science \& Engineering A, 558, 2012, 550-557.

2. Chajda J. and Grzelka M.: The algorithm of the gears measurement with a CMM. Proc. of XVI IMEKO World Congress, Wien, Austria 2000, 51-56.

3. Dybowski K., Sawicki J., Kula P., Januszewicz B., Atraszkiewicz R. and Lipa S. The effect of the quenching method on the deformations size of gear wheels after vacuum carburizing. Archives of Metallurgy and Materials, 61(2B), 2016, 1057-1062.

4. Gawroński Z., Sawicki J. Technological surface layer selection for small module pitches of gear wheels working under cyclic contact loads. Materials Science Forum, 513, 2006, 69-74.

5. Gawroński Z., Malasiński A. and Sawicki J. Elimination of galvanic copper plating process used in hardening of conventionally carburized gear 
wheels. International Journal of Automotive Technology, 11(1), 2010, 127-131.

6. Gräfen W., Edenhofer B. New developments in thermo-chemical diffusion processes. Surface \& Coatings Technology, 200, 2005, 1830-1836.

7. Gräfen W., Hornung M., Irretier O. and Rink M. Applications of low-pressure carburizing with high temperatures $\left(1000^{\circ} \mathrm{C}\right.$ to $\left.1050^{\circ} \mathrm{C}\right)$ in industrial practice. Haerterei-Technische Mitteilungen, 62(3), 2007, 97-102.

8. Grzelka M. The accuracy of the gear's measurement with the Coordinate Measuring Machine. Measurement Automation Monitoring, 2, 2004, 18-22.

9. Grzelka M. The gear's measurement with the CMM. Technical Transactions - Mechanics, 7, 2010, 33-40.

10. Heuer V., Loeser K., Schmitt G. and Ritter K. Integration of Case Hardening into the Manufacturing Line. AGMA Technical Paper, 11FTM23, 2011, 1-12.

11. IHI Machinery and Frnace Co. In-line heat treatment!? Next-generation heat treatment equipment. IHI Engineering Review, 44(2), 2012, 50-53.

12. Korecki M., Fujak W., Olejnk J., Stankiewicz M. and Wołowiec-Korecka E. Patent Application No EP 16000164.0, 2016.

13. Korecki M., Wołowiec-Korecka E. and Brewka A. Unicase Master - In-line, high-volume, low-distortion, precision case hardening for automotive, transmission and bearing industry. Proc. of 3rd International Conference on Heat Treatment and Surface Engineering in Automotive Applications, Prague, Czech Republic, 2016.

14. Korecki M., Wołowiec-Korecka E. and Glenn D. Single-piece, high-volume, low-distortion case hardening of gears, Thermal Processing, 9/10, 2016, 32-39.

15. Korecki M., Wołowiec-Korecka E. In-line, highvolume, low-distortion, precision case hardening for automotive, transmission and bearing industry. Proc. of 23rd IFHTSE Congress, Savannah, USA 2016, 1-7.

16. Kula P., Dybowski K., Wolowiec E. and Pietrasik R. "Boost-diffusion" vacuum carburising - Process optimisation. Vacuum, 99, 2014, 175-179.

17. Ratajczyk E. Coordinate measuring technique. Warsaw University of Technology Academic Publishing, 2005. 